\title{
Chamado do Pajé: regimes de memória, apagamentos e protagonismo indígena no baixo Tapajós
}

\section{The Call from the shaman:regimes of memory, erasure and indigenous protagonism in the lower Tapajós}

\author{
Edviges Marta loris ${ }^{1}$
}

\begin{abstract}
Resumo: O texto aborda os processos de reelaboração étnica e cultural que começam a ocorrer na virada para o século XXI entre vários povos indígenas do baixo rio Tapajós, e como eles configuram uma contra narrativa à historiografia oficial, que sucessivamente foi promovendo um apagamento das alteridades étnicas na região. A produção dessa contra narrativa ao apagamento é pensada como um processo de construção de um novo regime de memória que vai recolocando os indígenas e seus protagonismos na história, e na historiografia do baixo Tapajós. Nesse novo regime de memória não se trata somente de um adendo para incluir os indígenas e seus protagonismos nas páginas da história da região, mas de maneira crítica compreender como os próprios indígenas têm procurado construir a memória na atualidade, reafirmar suas origens étnicas e reelaborar a sua história em sua relação ao mundo colonial que os encapsulou. Palavras-chave: regimes de memória, historiografia, pajé Laurelino, etnogênese, baixo Tapajós.
\end{abstract}

\begin{abstract}
The paper approaches the processes of ethnic and cultural reelaboration that start to occur at the turn of the 21st century among several indigenous peoples of the lower Tapajós River, and how they set up a counternarrative to the official historiography, which successively promoted an erasure of ethnic alterities in the region. The production of this counter-narrative to the erasure is thought as a process of construction of a new regime of memory that is replacing the indigenous and their protagonism in the history, and in the historiography of the lower Tapajós. In this new regime of memory, it is not only an addendum to include the Indians and their protagonists in the pages of the history of the region, but critically to understand how the natives themselves have built memory today, reaffirmed their ethnic origins and elaborated on their history in their relation to the colonial world that encapsulated them.
\end{abstract}

Keywords: regimes of memory, historiography, shaman Laurelino, ethnic and cultural elaboration, lower Tapajósrd5.

\section{Da morte do pajé às reelaborações étnicas e culturais}

No dia 31 de maio de 1998 faleceu Laurelino Floriano Cruz, importante liderança política religiosa da comunidade de Taquara, localizada na margem direita do rio Tapajós, cujas terras foram sobrepostas pelos limites da Floresta Nacional do Tapajós (Flona

\footnotetext{
${ }^{1}$ Professora do Departamento de Antropologia da Universidade Federal de Santa Catarina - UFSC; e-mail: emioris@gmail.com
} 
Tapajós). Identificando-se como indígena kumaruara, oriundo do alto rio Arapiuns, Laurelino chegou nessas terras no final da década de 1930, onde se casou, primeiramente, com Maria Nicomédia e, mais tarde, com sua irmã Cândida. Ambas as irmãs eram filhas do casal Manoel Ribeiro e Izabel Francisca, os primeiros moradores de Taquara, e que são identificados como Munduruku. Desta relação, constitui-se extenso núcleo familiar, que cresceu e se consolidou ao longo das décadas, conformando a base dos grupos domésticos do que veio a ser conhecida como a comunidade de Taquara.

Laurelino tornou-se forte referência não só para a comunidade de Taquara, como para toda a região do baixo Tapajós 2 , por seus fortes poderes para tratar pessoas enfermas, para curar suas doenças e seus males. Conhecido como "médico da terra", Laurelino tratava também pessoas de fora que o procuravam em Taquara, assim como se deslocava uma vez por mês para a cidade de Santarém, onde centenas de pessoas o esperavam em fila, em frente ao barco que ficava ancorado no porto da cidade, para serem atendidas por ele.

As práticas de atenção e cura operadas por Laurelino, em suas manifestações cosmológicas e rituais, constituíam-se no principal fator articulador e dinamizador da organização sociopolítica e cultural da comunidade de Taquara, assim como do estabelecimento de relações com outros grupos sociais na região, com os agentes de órgãos do poder local ou da sua economia política. Entretanto, logo após o seu falecimento, na comunidade de Taquara começou a se processar uma profunda redefinição em seus modos de organização e articulação política, através da qual empreenderam significativa reelaboração de suas antigas tradições culturais, retomando manifestações rituais, língua, pinturas corporais, e passando a se reconhecer como uma comunidade política etnicamente diferenciada, reafirmando-se como pertencente ao povo Munduruku.

$\mathrm{Na}$ área da Flona Tapajós, logo depois, seguindo Taquara, também as comunidades de Bragança e Marituba passam por processo semelhante, e reafirmam-se como pertencentes ao povo Munduruku, identidade que até então era pouco referida. Juntas, as três comunidades articulam-se politicamente na demanda pelo reconhecimento e re-

\footnotetext{
${ }^{2}$ A região do baixo Rio Tapajós está localizada no sudoeste do Estado do Pará, em área categorizada pelo IBGE como microrregião do Médio Amazonas Paraense, mais comumente conhecida como Baixo Amazonas.
} 
gularização de suas terras como indígenas junto à FUNAI. Reconhecendo a legitimidade da demanda, o órgão indigenista encaminhou os procedimentos para a sua regularização, que se iniciaram em 2001, resultando na identificação de duas Terras Indígenas 3 , que já contam com portaria de delimitação assinada pelo Ministro da Justiça, em 2016. $\mathrm{Na}$ área da Flona Tapajós, a conformação desse processo de mobilização étnica entre as três comunidades e suas demandas por reconhecimento das terras indígenas redirecionou e redefiniu um longo processo de luta em defesa dos territórios, que estava em curso desde a década de 1970 (loris 2014).

Além destas três comunidades na Flona Tapajós, vários outros grupos domésticos de diversas comunidades por toda a região do baixo rio Tapajós e do rio Arapiuns também passaram a reafirmar pertencimentos a etnias que, em sua maioria, a literatura histórica afirmava não mais existir, como Borary, Arapium, Tapajó, Maytapu, Tupayú, Kumaruara ou Tupinambá. Juntos, estimados em cinco mil pessoas, estes grupos domésticos têm engendrado um processo de reconstrução das suas identidades indígenas e antigas tradições culturais, igualmente reelaborando manifestações rituais e simbólicas, além de demandar a demarcação de suas terras e estabelecer formas de organização política assentadas em bases étnicas.

Neste sentido, a emergência deste movimento de reafirmação das identidades indígenas tem significado uma alteração substancial na paisagem sociopolítica e cultural da região, nas formas associativas de organização política, assim como nos espaços territoriais, nos quais as "terras indígenas" também passaram a fazer parte (loris 2018; 2014). Em duas décadas de mobilização, os indígenas do baixo Tapajós e Arapiuns conquistaram o reconhecimento de quatro Terras Indígenas 4 , promovendo não só significativa reconfiguração na paisagem sociopolítica, cultural e territorial, mas também rein-

\footnotetext{
3 Terra Indígena Munduruku-Taquara e Terra Indígena Bragança-Marituba.

${ }^{4}$ Entre as terras indígenas em adiantado processo de regularização encontram-se: 1) Terra Indígena Munduruku-Taquara e 2) Terra Indígena Bragança-Marituba. Ambas tiveram estudos de identificação e delimitação em 2003, e portaria declaratória da FUNAI em 2009, e em 2016 do Ministro da Justiça; 3) Terra Indígena Maró, com estudos de identificação e delimitação em 2008, e portaria declaratória da FUNAI em 2011; e 4) Terra Indígena Cobra Grande, com estudos de identificação e delimitação em 2008, e portaria da FUNAI em 2015. Também foram realizados estudos de identificação das terras dos Mundukuru que se encontram na margem direita do rio Tapajós, no limite sul da Resex Tapajós-Arapiuns, e das terras dos indígenas Borary de Alter do Chão, porém nunca foram publicados os resumos dos seus respectivos Relatórios; e foram realizados vários levantamentos entre os indígenas que se encontram no interior da Resex Tapajós-Arapiuns, os quais indicaram a necessidade de criação de várias terras indígenas, para os Tupinambá, Arapium, Tupaiú, Kumaruara e Arara Vermelha.
} 
serindo a temática étnica-indígena no âmbito das discussões e relações locais de poder, assim como das atenções acadêmicas científicas (loris 2005; 2014; Bolanõs 2006; Vaz 2010; Mahlen 2015; Fiqueiredo 2017).

Paralelamente aos procedimentos conduzidos pela FUNAI, no contexto regional destacam-se também iniciativas e medidas implantadas pelos poderes públicos em relação às demandas e reconhecimento dos direitos territoriais das populações indígenas. No município de Belterra, por exemplo, as atenções refletiram-se no ordenamento do Plano Diretor Participativo do município, sancionado (Lei $\mathrm{n}^{\circ} 131$ ) em 22/02/2007, no qual as terras indígenas dos Munduruku de Taquara, Bragança e Marituba foram reconhecidas e definidas como "Zonas Especiais de Interesse Cultural” (Art. 37). Em ato contíguo, a Prefeitura também criou a Coordenação Indígena, alocada na Secretaria de Planejamento e Gestão, e reconheceu as escolas de ensino fundamental em suas aldeias como sendo indígenas, devendo, por essa razão, conduzir um plano de ensino diferenciado. Esses esforços na área da educação se juntaram aos implantados também pelas Prefeituras de Santarém e Aveiro, que reconheceram e incluíram as escolas indígenas em seus programas governamentais.

Estas ações de órgãos governamentais -do nível federal ao municipal- ressaltam o reconhecimento dos povos indígenas e de sua mobilização frente às demandas junto aos poderes públicos, e também demonstram a importância que passaram a ter na composição sociopolítica e cultural na região. Depois de um longo silêncio sobre os indígenas no baixo Tapajós, as políticas públicas têm sido obrigadas a inseri-los novamente em suas pautas de discussão e governança, e a incluí-los como beneficiários de seus programas administrativos. Assim, no "despertar dos mortos" (Benjamin 1985), a emergência do movimento de reafirmação étnica reconfigurou e trouxe à vida, e ao campo das relações sociopolíticas locais, a existência de grupos indígenas, que passam a se organizar e se empoderar para fazer valer seus direitos.

Além da reconfiguração da composição sociopolítica, cultural e dos espaços territoriais do baixo Tapajós, a emergência desse processo de reafirmação étnica na virada para o século XXI também coloca os indígenas outra vez em existência na história da região, onde, desde finais do século XIX, quase não há registro da presença de gru- 
pos etnicamente distintos. Apesar das descrições iniciais, que registraram numerosos e etnicamente diversificados povos, em pouco mais dois séculos de colonização no vale do Tapajós praticamente não há mais referência sobre os Tupinambá, Tupayu, Tapajó, Arapium, Borary, Corarienses, Comandy, Maytapu, encontrados na sua foz quando as primeiras naus portuguesas a adentraram no século XVII (Santos 1999; Parker 1985; Menéndez 1992, 1981; Bates 1979[1863]; Ribeiro 1979; Meggers 1972; Nimuendaju 1949).

Na segunda metade do século XIX, não obstante os viajantes naturalistas que navegaram ao longo do rio Tapajós referirem-se aos nativos que encontraram, e que Ihes prestaram serviços, como "índios", eles não registraram nenhuma nominação étnica, exceto por um grupo doméstico Munduruku encontrada no rio Cupari, e acima, no alto Tapajós (Bates 1979[1863]; Coudreau 1977[1897]). Adiante, no século XX, de modo geral esses povos passaram a ser identificados como parte de um campesinato amazônico, e são referenciadas como "caboclos" ou "ribeirinhos", categorias cujas definições tendem a subtrair vínculos em relação aos diferentes pertencimentos étnicos ou territoriais, em geral descritos como "descendentes de índios destribalizados ou aculturados" (Santos 1999; Wagley 1985; Parker 1985; Lins e Silva 1980). Nas últimas duas décadas tenderam a ser identificados como "populações tradicionais", porém, ainda assim sem referências a pertencimentos étnicos (loris 2014; 2009).

Ao longo da história colonial e pós-colonial do baixo Tapajós podemos encontrar posições que buscam invisibilizar e proscrever a existência de modos diferenciados de organização étnicos e culturais, tanto nas compreensões historiográficas produzidas sobre a região e seus habitantes, quanto nas estratégias maiores de poder que se sucederam no tempo. Elas foram sucessivamente apagando a presença indígena na região, atribuindo-Ihes uma condição pretérita e esvanecida em decorrência do encontro colonial. Contra a correnteza, todavia, a emergência dos processos de reafirmação étnica no baixo Tapajós, que se observa na virada para o século XXI, produz uma contra narrativa à do apagamento, colocando os indígenas novamente em existência na história do baixo Tapajós, e fazendo valer suas demandas nas mesas de negociação do poder, do local ao nacional. 
Nesse sentido, tenho proposto pensar a produção dessa contra narrativa ao apagamento -recolocando os indígenas na história, e na historiografia no baixo Tapajóscomo um processo de construção de um novo regime de memória nos termos que $\mathrm{Pa}$ checo de Oliveira (2016) nos apresenta, para compreender os modos como os indígenas estão concebendo e arquitetando a memória na contemporaneidade, contrapondo-se às narrativas oficiais, que tem excluído sua participação e seu protagonismo na formação do Brasil. Contudo, nesse novo regime de memória, no qual os indígenas "são os principais artífices" (p.29), não se trata somente de reinscrever um adendo entre as linhas da história para incluir os indígenas e seus protagonismos, mas de maneira crítica compreender como os próprios indígenas têm procurado construir a memória, reafirmar suas origens e pertencimentos étnicos, e reelaborar a história em sua relação com o mundo colonial que os encapsulou (Balandier 1993[1955]).

\section{Regimes de memória e a produção historiográfica sobre os indígenas no Brasil}

Em livro recentemente publicado, João Pacheco de Oliveira (2016) traz à discussão a necessidade urgente de revisão do paradigma historiográfico dominante em relação à participação dos indígenas na formação do Brasil. Como destaca, desde as primeiras formulações sobre a história do Brasil no século XIX aos historiadores marxistas no século $X X$, "a presença indígena na formação da nacionalidade é tratada de forma exotizante e repetitiva, como fruto exclusivo de acasos, incidentes menores e relatos pitorescos" (p.12). Nesse sentido, demonstra como a narrativa que se construiu sobre a formação do Brasil produziu um apagamento dos indígenas e de suas participações frente aos avanços do projeto colonizador, assim como adiante, no projeto de construção da nação. A narrativa construída, suportada por categorias coloniais de cunho evolucionista, definiu o lugar e o momento em que os indígenas aparecem:

eles são anteriores ao Brasil... Uma vez iniciada [a colonização], os indígenas só poderiam ser concebidos como flores que fenecem, que precisam ser descritas e compreendidas antes que murchem e desapareçam. A superioridade tecnológica e militar dos colonizadores, as violências e epidemias dariam conta de explicar a sua extinção (p.47-48).

Pacheco de Oliveira chama atenção de que esta narrativa, conferindo uma imagem idílica, romantizada do indígena como símbolo da terra, porém pretérito à formação 
da nação brasileira, foi produzida na segunda metade do século XIX, e está diretamente associada à produção imaginativa do Brasil como nation building. Mais precisamente, assinala o autor, foi durante $o$

Segundo Império, quando o projeto de nação se elabora a partir dos debates sobre migração e o fim da escravatura, sem atribuir aos indígenas qualquer outra função que a de símbolo da terra, que essa narrativa se estrutura, ganha autor (a monumental história geral de Varnhagen) e instituição mantenedora (o IHGB do Rio de Janeiro e, posteriormente, suas sedes provinciais), internalizando-se no pensamento da elite e de setores populares (p. 50).

Desconstruindo a narrativa do inexorável fenecimento atribuído ao indígena no contato com o colonizador, Pacheco de Oliveira ressalta as noções de causalidade e fatalidade com que se explana a chegada dos portugueses, sem qualquer reação por parte dos indígenas, afiançando uma condição efêmera deste encontro e, como subproduto, atribuindo pouca importância aos indígenas na conformação colonial da América Portuguesa. Das versões mais recentes, que corroboram a supressão dos indígenas da economia política nacional, as críticas do autor recaem especialmente sobre a noção de "ciclos", que tem instrumentalizado as análises históricas sobre as distintas formas dominantes de exploração econômica pelas quais o Brasil teria atravessado, sejam extrativas, agrícolas ou industriais. Seus estratagemas analíticos abstraem a participação efetiva de seus agentes, obscurecendo assim os sujeitos na consolidação destas formas de exploração econômica, como no caso dos indígenas.

Assim, obscurecidos como produtores de economia, os indígenas desvanecemse em imagens como pequenas reminiscências de um frágil, doce e inocente autóctone da terra, exótico, passado. E, convenientemente, obscurece a exploração do trabalho escravo a que os indígenas foram submetidos durante toda a colonização, inclusive paralelamente à escravidão negra. Como em outro texto Pacheco de Oliveira e Rocha Freire (2006) esclarecem, a escravidão dos indígenas foi durante os dois primeiros séculos de colonização a principal fonte de trabalho e sustentáculo da consolidação da colônia Brasil: "Entre 1540 e 1570, em São Vicente, no sul, e Pernambuco, no nordeste, foram instalados cerca de 30 engenhos movimentados por milhares de escravos indígenas" (p.39). Não se trata, adverte Pacheco de Oliveira (2016: 26), de pura e simples omissão, mas de uma narrativa construída estrategicamente para diluir o indígena como 
se fosse acaso de pouca importância, até que, dissolvido, desaparecesse no horizonte de construção do projeto de nação posta em marcha na segunda metade do século XIX, durante o segundo reinado, e que atravessou o século $X X$.

Na mesma direção, as críticas do autor se direcionam também aos modos como certas correntes da Antropologia tem abordado a conformação dos povos indígenas em sua diversidade étnica e em relação com a sociedade nacional (colonial), os quais igualmente tenderam a corroborar o paradigma da pouca relevância dos indígenas, e de seu fenecimento frente ao contato com o mundo colonial. Suas observações dirigem-se primeiramente aos propósitos de intelectuais que, atuantes em períodos anteriores à década de 1970, apelavam por uma postura humanitária de proteção aos indígenas, acionando discursividades que atentavam para um moral culposo em relação ao extermínio e etnocídio que Ihes havia sido infringido. Contudo, ainda que tal posição intentasse a defesa e proteção dos povos indígenas, ela não questionava os sistemas de dominação e violência que a tutela impôs, nem a pouca relevância atribuída aos indígenas na construção do Brasil.

As ressalvas do autor se direcionam ainda aos estudos antropológicos que, em seus esforços de afirmar a diversidade, suas especificidades culturais, dedicaram-se, todavia, a apreender a organização social e a cosmologia de cada povo indígena como se eles fossem sistemas isolados e autônomos e, sobretudo, como se pudessem ser apreendidos "fora da história". Desse modo, tomados como unidades autoexplicativas e atemporais, tal percepção pouco tem ajudado a compreender quando os indígenas -muitas vezes estudados em apenas uma ou outra aldeia, com restritos "informantes"trazem ao pesquisador informações que escapam a esse enquadramento circunscrito, como aquelas sobre os efeitos que o poder colonial tem causado sobre eles. Pacheco de Oliveira (2016: 14) assinala que esta perspectiva isolou os indígenas e deixou de fora "o mundo colonial dentro do qual os indígenas viviam, inseridos em duras relações de dominação", assim como desconsiderou as formas variadas de resistência e de acomodação. Desse modo, ela também deixou de "conhecer as formas concretas pelas quais as coletividades indígenas lograram resistir, se organizar e continuar a atualizar sua cultura na contemporaneidade, inclusive formulando projetos de futuro". 
Com essa compreensão, Pacheco de Oliveira advoga a necessidade de superação desta perspectiva histórica excludente dos indígenas na formação do Brasil, clamando por uma revisão urgente deste paradigma, como exercício de implosão desta narrativa construída no século XIX, que exotiza e ausenta o protagonismo indígena na construção do Brasil. Para tanto, assinala que se impõe anular os efeitos de verdade que essa narrativa tem produzido para, então, instituir outra chave de leitura da história do país que possibilite recolocar os indígenas como agentes efetivos na construção do Brasil. E a chave de leitura que oferece, para compreensão da efetiva presença indígena nos contextos históricos em que tais representações foram formuladas, possibilita pensar os regimes de memória como modos de explanar os múltiplos regimes de alteridade que se constituíram ao longo da história do Brasil. Destes, destaca cinco regimes de memória que revelam diferentes modos de representações em relação aos indígenas, desde a chegada dos portugueses no início do século XVI aos dias atuais.

$\mathrm{Na}$ atualidade, a memória que os movimentos indígenas buscam construir contrapõe-se às narrativas oficiais que têm ofuscado o seu protagonismo, aos regimes de memória que produziram sucessivamente o apagamento dos indígenas na história e formação do Brasil. Para o autor, um regime de memória propicia contar uma história, e a sua apreensão deve associar as "ações, narrativas e personagens lhes integrando em formas de construção de significados" (p.26). Mas essa história não poderá ficar fixada em um único ponto de vista; mas deve ser elaborada das muitas histórias que a constituem e de seu entrelaçamento. Em sua busca, portanto:

\footnotetext{
o investigador não deve se limitar a uma documentação produzida por fonte oficial e que reflita uma perspectiva supostamente canônica em relação àquele assunto: precisa explorar a diversidade de fontes e a multiplicidade de relatos possíveis, beneficiando-se do resultado de pesquisas antropológicas e históricas (p.29).
}

Assim, discorrer sobre os regimes de memória - pensados como uma arquitetura de memória que integra fragmentos em uma totalidade, instaurando um sentido compartilhado - nos impõe primeiramente problematizar a construção das narrativas que têm sido produzidas sobre os povos indígenas, suas fontes, seus contextos sociopolíticos, bem como motivações e interesses (materiais e ideológicos). É preciso, portanto, atentar aos entrecruzamentos da produção destas narrativas com as redes de poder que as sus- 
tentam. Todavia, crítico para os regimes de memória, tal perspectiva também possibilita igualmente compreender os modos como os próprios indígenas têm procurado construir a memória na atualidade, como artífices de outra arquitetura de memória, que tem se contraposto àquelas que desconsideraram a sua presença na formação do Brasil.

É nesse sentido que procuro compreender os processos de reelaboração étnica e cultural que se conformaram entre os Munduruku na virada para o século XXI, assim como entre os demais povos indígenas no baixo Tapajós, como constituindo um novo regime de memória a confrontar as narrativas historiográficas dominantes, que desconsideraram não só o seu protagonismo, assim como a sua própria existência. Desse modo, eles aportam com narrativa alternativa à do apagamento, recolocando os indígenas novamente em existência na história do baixo Tapajós, por onde reafirmam sua alteridade e fazem valer suas demandas nas mesas de negociação do poder.

\section{Os Indígenas do baixo Tapajós: sucessivo apagamento das alteridades}

Como tenho assinalado em trabalhos anteriores (loris 2018, 2017; 2011), a presença indígena foi suprimida da narrativa historiográfica sobre a região do vale do médio e baixo Tapajós, sem que, ao menos, fosse oferecida uma compreensão de como esse processo sucedeu. E, principalmente, sem que fosse oferecida uma compreensão mínima sobre quem eram e o que se passou com aqueles diversos povos que foram registrados pelos primeiros colonizadores quando adentraram a foz do rio Tapajós no início do século XVII para impor a sua ocupação e dominação. Como estes primeiros registros assinalaram, a região do baixo Tapajós era densamente habitada por uma diversidade de povos, porém, em pouco mais de duzentos anos de colonização, eles vão deixando de aparecer em suas anotações (Menéndez 1992, 1981). Entretanto, praticamente não há informações que esclareçam o que teria acontecido com eles, para terem desaparecido de modo tão talhante da narrativa e dos registros oficiais, e assim passam a ser tomados como povos extintos.

Não obstante os grandes eventos históricos que se sucederam na região ao longo de três séculos desde os tempos coloniais, relacionados às missões Jesuítas, ao Diretório dos Índios, ou à Cabanagem, são praticamente desconhecidos os modos de interação entre os indígenas e o projeto colonizador, e de inserção em cada uma dessas situações 
históricas, assim como os modos como alteraram as organizações socioculturais nativas e suas bases territoriais. Ao se procurar a sua compreensão, tem-se a impressão de que tudo se passa como se a chegada do colonizador de pronto anulou a presença dos povos indígenas na região.

Em um dos raros textos sobre os índios Tapajó que, ao lado dos Tupinambá, dominavam numérica, política e culturalmente a região do baixo Tapajós quando a colonização iniciava, Nimuendajú (1949: 98) alegava que "da língua dos Tapajó só conhecemos três nomes próprios: o da tribo, o do chefe Orucurá e o do diabo: Aura". Ele achava que este povo teria deixado de existir em 1723, quando acompanhava a transferência que os jesuítas fizeram da Missão Tapajó para a região do rio Arapiuns. Na década de 1960, Betty Meggers (1972) afirmava que tudo o que se sabia sobre os Tapajó é que "não eram Tupi". Em seu mapeamento etno-histórico da região Tapajós-Madeira, Menéndez (1992: 318) assinalava que dos Tupinambá, "trinta anos depois de iniciada a catequese na região, pouco restava da populosa aldeia situada na foz do Tapajós e, neste tempo, já não se falava mais dos Tupinambá como etnia". Fundada em 1661 na foz do Tapajós, em quatro anos a Missão Tapajó já era considerada a mais importante da Província do Grão-Pará e Maranhão, reunindo grupos de Tapajó, Tupinambá, Arapium, Corarienses, e Comandy.

Do mesmo modo que é grande o desconhecimento sobre os indígenas e suas formas de organização sociopolítica e cultural, também é o desconhecimento sobre os cem anos de dominação das missões jesuíticas no baixo Tapajós, entre os séculos XVII e XVIII, as quais foram estabelecidas em cinco pontos, onde indígenas de várias famílias linguísticas eram estocados, tendo o Nheengatu como idioma oficial (Menéndez 1992, 1981). Não há estudos que esclareçam as relações estabelecidas com os indígenas nas missões, nem as estratégias para seu convencimento e condução às reduções, para a sua conversão; enfim, como se construíram e efetivavam as formas e os alcances dessa dominação? E sobre que povos efetivamente? Igualmente, desconhece-se a extensão das políticas pombalinas do Diretório dos Índios que sucederam as Missões jesuíticas, depois de sua expulsão, em meados do século XVIII, e instituídas pelo governador da Capitania do Grão-Pará, Mendonça Furtado, que navegou o Tapajós em 1758, e procedeu com a instalação das "vilas" e "lugares", em substituição às suprimidas missões jesuíticas. Os nomes de povoados como Vila Boim e Vila Franca são testemunhos da 
instituição desse ato colonial; porém, praticamente nada se sabe sobre a participação e os alcances de tal política de Estado para os indígenas, que tinha como meta e estratégia a miscigenação da população nativa.

Em relação ao movimento da Cabanagem, talvez seja o evento ainda mais instigante. Ocorrido na segunda metade da década de 1830, já no Brasil independente, configurou um violento campo de batalhas que assolou de modo significativo os povos nativos, nos confrontos ou na repressão subsequente, os quais suprimiram um quarto da população do Grão-Pará (Bessa Freire 2011; Harris 2010; Mahlen 2008; Parker 1985; Moreira Neto 1988). Porém, ao mesmo tempo em que a bibliografia histórica reconhece a massiva participação dos indígenas no movimento, pouco se sabe sobre quem eram os povos e suas respectivas participações, assim como dos desdobramentos com o fracasso do movimento. No baixo Tapajós, locais como Santarém, Vila Franca, Alter do Chão e Pinhél, onde as missões Jesuíticas tinham sido fundadas, constituíram importantes redutos de luta e resistência dos Cabanos, assim como Ecuipiranga, localizada à margem do rio Amazonas (Vaz 2010; Harris 2010; Mahlen 2008). Em Pinhél, onde se encontram os indígenas Maytapu, ainda se observam vários espaços cavados no solo, que são atribuídos às trincheiras de combate construídas durante a revolta, assim como se ouvem detalhadas narrações sobre confrontos e a participação de seus antepassados naqueles confrontos. Entretanto, embora algumas teses tenham destacado a participação dos indígenas no movimento no baixo Tapajós (Vaz 2010; Harris 2010; Mahlen 2008), ainda não desfrutamos de estudos que esclareçam a diversidade e o alcance e a efetiva participação indígena no movimento, e que avaliem as suas consequências para as formas de organização sociopolíticas nativas e de ocupação territorial, situação para a Amazônia em geral.

É urgente que esforços sejam empreendidos para uma compreensão de modo mais efetivo sobre os significados e alcances desse movimento sobre os povos indígenas no baixo Tapajós, cujos territórios ostentam marcas evidentes dos seus embates, e as pessoas rememoram em suas narrativas com ricos detalhes. Neste sentido é fundamental que se dê especial atenção a estas narrativas, buscando compreender os sentidos presentes nos relatos sobre as fugas, os temores vividos, pelo que atribuíam como sendo causados pelas "guerras", que tão frequentemente se ouve entre as comunidades 
indígenas da região. Na aldeia de Bragança, por exemplo, seu Orlando rememorava as histórias ouvidas pela sua avó, que:

Sempre contava que eles viviam lá [no interior da mata], viviam assim por causa de que ficavam com medo da guerra, porque era tempo que tinha guerra. Eles tinham medo porque viam que o pessoal chegava e atacavam. Os brancos atacavam, aí ficaram, preferiram fugir e ficar mais escondido por lá, né, pra dentro da mata pra ninguém encontrar eles, pra eles não ser atacado.

Na mesma direção, Leo Tupayu, da aldeia de Anigalzinho no rio Arapiuns também reproduzia as histórias ouvidas de seus avós, explicando porque e como passaram muito tempo fugindo por dentro da mata:

Foi na época que eles foram morar dentro da mata fugindo da guerra, da guerra, entendeu? Foi lá onde não podiam fazer fogo de noite, só de dia. Não, não fazia fogo nem de dia; para não chamar atenção. Eles moravam em buracos. Eles moravam em buracos porque eles tinham medo que as pessoas vinham buscar eles pra ser escravo, para ir para a guerra. Porque o exército vinha, pegava e levava lá para a guerra. Quem não ia, morria. $O$ jeito era fugir para o mato, lá onde ficaram morando no buraco.

São fragmentos de relatos, mas que dão indicativos importantes de processos de deslocamento que os indígenas podem ter sofrido, e como tal não eram mais encontrados ao longo das margens do Tapajós no final do século XIX (Coudreau 1977[1897]). Todavia, como nos adverte W. Benjamin (1985), se o passado se encontra em ruinas é preciso valorizar os seus fragmentos como vestígios importantes para a sua reconstrução, pois entende que eles podem ter muito a nos contar. É a compreensão de que "os restos são apenas restos, mas muitas vezes são os únicos testemunhos que permitem o acesso ao passado" (Otte e Volpe 2000:40). É nesse sentido que penso nas frequentes referências sobre os tempos de guerras, dos corre corre, das fugas, do viver escondido em buracos, que tão repetidamente se ouve entre os indígenas do baixo Tapajós, e do quanto elas sugerem dinâmicas e direções para onde poderiam ter ido muitos dos povos indígenas que foram descritos como extintos. Assim, entendo que é preciso tomar estes relatos como chaves importantes para a compreensão do passado indígena no baixo Tapajós, das suas mobilidades, dos modos e direções que suas dispersões/migrações tomaram, buscando simultaneamente compreender como a sua presença tem sido suprimida das páginas da história.

Nesta direção, ainda, é importante considerar como os indígenas que participa- 
ram da Cabanagem são descritos e representados, os quais, de modo geral, têm sido descaracterizados como povos etnicamente articulados. No baixo Tapajós, como em geral para a Amazônia, apesar de a literatura ressaltar a massiva participação dos indígenas na Cabanagem, e as narrativas locais são plenas de referências a ela, em termos da historiografia eles geralmente aparecem como um genérico "tapuia", comumente desqualificado em termos de pertencimento ou distinção étnica (Harris 2010; Menéndez 1992, 1981). Em seu mapeamento etno-histórico da região dos rios Tapajós e Madeira entre os séculos XVI-XIX, Menéndez (1992: 322), por exemplo, identifica os indígenas que lutaram ao lado dos cabanos como "índios já destribalizados, "descidos" ou descendentes de "descidos", cujas aldeias originais em parte já não mais existiam. É parte desta população "tapuia" internada em pequenos grupos com seus tuxauas, que se junta aos cabanos" (ênfase no original). É interessante notar que, apesar de assinalar para uma forma de organização política própria dos indígenas articulada em torno dos seus "tuxaus", ao apresentá-los em termos de "destribalizados, descidos", o autor renega as suas caracterizações étnicas, ao mesmo tempo em que reforça o preconceito e o estereótipo do índio aculturado, destituído de referências culturais; além de estabelecer uma clivagem perversa entre supostos verdadeiros e falsos índios, que tende a corroborar com o apagamento da presença de povos etnicamente constituídos.

Esse processo de apagamento dos diferentes povos indígenas no baixo Tapajós também se revelava nos modos de descrição que encontramos nas primeiras décadas do século XIX, os quais, quando mencionados, o são por um genérico "índio" ou "indígena", sem referência às suas etnias. No compêndio que produziu para explanar, pela primeira vez, o número e a classificação racial da população do Estado do Grão-Pará em finais da década de 1830, simultaneamente ao evento da Cabanagem, o militar luso Antônio Ladislau M Baena (2004[1839]: 221), reconhecia que na região do vale do Tapajós eram os "Índios que fazem a maior força numérica da população, e também o único recurso para o trabalho para o país"; porém não identificou nenhuma de suas etnias, os quais foram arrolados no cômputo geral como "livres", junto com os "brancos", em oposição aos "escravos". Também adiante, como já assinalamos, os viajantes naturalistas europeus que navegaram ao longo do rio Tapajós na segunda metade do século de XIX, referiamse aos nativos como "índios", mas não registraram nominações étnicas, exceto pelos 
Munduruku no alto rio (Bates 1979[1863]; Coudreua 1977 [1897]). Ainda assim, quando o explorador francês Henri Coudreau navegou o vale do Tapajós a pedido do governo do Pará em 1895, ele estimou que os Munduruku resumiam-se a "cerca de uns 1000 a 1400 no máximo", para os quais previa sua inevitável extinção: "eles desaparecerão inteiramente, de vez que vão de pouco se miscigenar com a população civilizada. O que se considera ainda hoje como o 'sertão dos mundurucu' brevemente estará transformado em nada mais que a tapera de uma sinistra tribo extinta" (1977: 126).

Neste mesmo caminho, a própria Antropologia também foi reforçando a perspectiva do desaparecimento dos Munduruku, assim como dos demais povos indígenas no baixo Tapajós. Os antropólogos Robert Murphy e Yolanda Murphuy (1954), quando estudavam as mudanças culturais entre os Munduruku na década de 1950, igualmente projetavam o seu gradativo e inexorável desaparecimento. Para eles,

\begin{abstract}
toda evidência histórica aponta para a conclusão de que, em meados do século XIX, a cultura aborígine dos Mundurucu estava desaparecendo nas regiões periféricas. Conserva-se, todavia, mais bem preservada na área do alto Tapajós... O baixo Tapajós apresentava um caso claro de assimilação gradual da população indígena dentro do tipo caboclo da Amazônia (p. 10).
\end{abstract}

Nimuendajú (1949), que também andou pelo baixo Tapajós na década 1920, apesar de reconhecer falantes e a vitalidade do nhengatu na região, não registrou referências étnicas.

As referências que se seguem foram reforçando o apagamento de povos etnicamente articulados no baixo Tapajós, e os grupos domésticos que se encontravam espalhados ao longo de suas margens passam a ser reconhecidos como descendentes de indígenas, porém destituídos de referências étnicas ou culturais, como formadores do campesinato Amazônico, e identificados como "caboclo" ou "ribeirinho". Discorrendo sobre o processo de transformação que os indígenas teriam sofrido na Amazônia, e a emergência histórica do 'caboclo' como categoria social na região, o texto de Parker (1985), por exemplo, é ilustrativo desta perspectiva, definindo a sua conformação como produto de "Ameríndios destituídos e privados culturalmente e descendentes mestiços engajados em inconstantes atividades de subsistência e coleta de produtos florestais ( $p$. 35)". Eu mesma, quando visitei pela primeira vez as comunidades na Flona Tapajós para um levantamento, em 1996, elas, de modo geral, eram-me referenciadas pelos repre- 
sentantes das instituições e poderes locais como comunidades de "caboclos", "caboclos do Tapajós", mas também, com bastante frequência, como "comunidades ribeirinhas". Ainda em Santarém, quando perguntei sobre a existência de indígenas na região, fui informada de que "ainda restavam alguns em Alter do Chão".

Poderíamos nos estender com mais exemplos, ampliando os levantamentos. Todavia, penso que os apresentados são suficientes para demonstrar como vamos encontrando no baixo Tapajós, como também em outras partes da Amazônia de colonização antiga, uma narrativa que vai se construindo e apagando os indígenas das páginas da história, diluindo os diferentes povos em um tapuia destribalizado, miscigenado e tornado caboclo, até assumir a sua extinção, ou ainda restando alguns. E esse apagamento dos indígenas e de suas alteridades étnicas, que foi se processando ao longo da história da região, eu tenho procurado pensar como um processo de produção de um regime de memória, nos termos que Pacheco de Oliveira (2016) apresenta, o qual se assenta em um "sistema de verdades" que sucessivamente foi corroborando a narrativa do desaparecimento dos indígenas. Uma narrativa que foi suprimindo a alteridade, dissolvendo as diferenças, para fazer emergir um projeto de nação que buscava eliminar a diversidade étnica e racial do país.

Entretanto, contrapondo-se ao regime de verdades que afirmava o fim dos indígenas no baixo Tapajós, os processos de reafirmação étnica e cultural que se conformaram na virada do século XXI promoveram uma quebra àquela narrativa, que não apenas excluiu o protagonismo dos indígenas -apesar de oficialmente serem reconhecidos como o "único recurso para o trabalho para o país" (Baena 2004[1839]) -, como excluiu a sua própria presença. É a quebra de um tempo homogêneo, a quebra da narrativa progressista linear dos vencedores a que W. Benjamin (1981) conclamava que fosse enfrentada, que no "acordar dos mortos" faz acordar a história indígena que se afirmava estar sepultada. Começam assim a produzir um novo regime de memória no qual os indígenas tecem outra arquitetura de memória, elaborando uma contra narrativa àquelas que desconsideraram sua própria existência. Nesse novo regime a memória da história e da cultura indígena não se revela como exercício de abstração, mas impressa e renovada na experiência das suas práticas cotidianas, nas suas organizações políticas, assim como em seus corpos. 


\section{Ao clamor do pajé, o não esquecimento da cultura indígena}

Como mencionamos anteriormente, o movimento de reafirmação étnica e territorial entre os indígenas Munduruku de Taquara teve início logo após o falecimento de Laurelino da Cruz, em maio de 1998. De modo mais detalhado, tenho analisado em outros trabalhos as motivações e condições que desencadearam esse processo de reafirmação étnica e territorial entre os indígenas em Taquara, Bragança e Marituba, e apontado tanto para as forças internas como externas que se conformaram favorecendo a sua emergência e consolidação (loris 2018; 2014; 2009; 2005). Do ponto de vista externo, assinalo a sua relação com os conflitos fundiários relacionados à sobreposição dos seus territórios com os limites da Flona Tapajós. Do ponto de vista interno, analiso a sua estreita relação com a morte do principal líder político-religioso de Taquara, o pajé Laurelino Floriano Cruz, e o vácuo que sua partida causou entre os grupos domésticos na comunidade de Taquara, cuja organização sócio-política e econômica estava assentada nos trabalhos xamânicos por ele conduzidos. Assim, procurei demonstrar como a emergência do movimento de reelaboração étnica e cultural respondia às necessidades de superação da crise de representação política instaurada com sua morte. Ela foi superada na busca por suas antigas referências étnicas e culturais, e no encontro com elas passam a viver um novo modo de organização sociopolítica, reafirmando-se como étnica e culturalmente distintos e reconhecendo-se como pertencentes ao povo Munduruku.

Nesse texto, para finalizar, gostaria de assinalar como esse processo de reafirmação étnica e territorial, que reinscreve os indígenas na história do baixo Tapajós, tem configurado a construção de um novo regime de memória (Pacheco de Oliveira 2016), que se expressa na experiência das práticas cotidianas dos indígenas, nas suas formas de organização política, e em seus corpos. Ele atende a um chamado daquele que se foi para que os seus descendentes não esquecessem a sua cultura, as suas origens; e o não esquecimento é exercício que se conforma em ações culturais e performances rituais.

Poucos meses antes de morrer, Laurelino havia gravado, em fitas cassetes, Iongas entrevistas concedidas a Florêncio Vaz Almeida, indígena Maytapu, frei franciscano, antropólogo e professor da UFOPA, em que relatava sua história de vida, seus trabaIhos em curar pessoas. Nas gravações, Laurelino finalizava solicitando aos seus filhos 
e netos que não se esquecessem da sua "cultura indígena". Essas fitas ficaram com seus familiares que, depois do falecimento, no luto que se seguiu, passavam tempos juntos escutando-as. E foi do pedido que ouviam para que não esquecessem a "cultura indígena" que brotou o impulso para atender ao chamado, porém, não apenas para não esquecer, mas para viver e afirmar a "cultura indígena". Como explicava Assis, um dos filhos de Laurelino, e então vice-Cacique:

Depois da morte de meu pai nós passamos um longo tempo ouvindo as fitas, uma fita depois da outra. Nós começamos a nos perguntar sobre várias coisas. Se o desejo de nosso pai era que a gente não esquecesse nossa cultura, que nós reconhecesse nossa cultura, que nós somos mesmo índios, por que, então, nós não reconhecemos que somos índios? É por causa de vergonha? Então, vamos colocar nossa vergonha de lado e ser o que nós realmente somos.

Seguindo o impulso de atender ao desejo, ao pedido de Laurelino que ouviam das fitas, os indígenas de Taquara engajam-se firmemente no propósito de reelaborar seus modos de vida e de organização sociopolítica, para que estivessem acordados em bases que compreendiam ser suas origens e referências étnicas, afirmam-se como pertencentes ao povo Munduruku, e passam a demandar o reconhecimento de suas terras como indígenas. O atendimento a esse chamado responde à busca de superação à crise causada pela ausência daquelas práticas simbólicas cotidianas relacionadas aos trabaIhos xamânicos de Laurelino, e que os conectavam ao universo e ao passado indígena. Sem ele, os elos de continuidade com aquele universo poderiam se dissolver. O não esquecimento, a permanência desses elos, dependeria, portanto, daqueles que ficaram mantê-los em vigor. Como assinala Turner (1974), é nas fases de reajustamento das crises sociais -como a enfrentada pela comunidade de Taquara com o falecimento da sua principal liderança político-religiosa- "que tanto técnicas pragmáticas quanto ações simbólicas alcançam sua expressão mais elaborada" (p. 41). Nestas situações, ocorre "um cruzamento de influências entre formas novas e tradicionais de communitas, levando em alguns casos ao restabelecimento de formas tradicionais que há muito tempo se encontravam debilitas ou esmaecidas" (p. 172).

Nesta direção, o chamado para o não esquecimento a que clamava o pajé Laurelino era, de fato, um chamado para um novo regime de memória, que não deixasse submergir a cultura indígena, que fundamentava a organização sociopolítica e cultural 
de Taquara. A constância da memória de sua cultura indígena, porém, não resultaria em exercícios de abstração, de escrita, mas constituindo-se e se renovando nas suas práticas de vida cotidianas, nas novas formas de organização política, nas performances rituais, assim como em seus corpos, em seus adereços e pinturas, valorizando-os como elementos diacríticos de alteridade. São nessas práticas cotidianas que se lançam em tarefa messiânica de "libertar o passado indígena", tal como sugeria W. Benjamin (1981), para inscrevê-los novamente na história do baixo Tapajós, ou melhor, reinscrever a existência e permanência dos Munduruku na região. Atendendo ao chamado do pajé, reinscrevem-se também os Borary, os Tapajó, os Maytapu, os Arapium, Jaraki, Kumaruara e outros povos que haviam sido eliminados da narrativa historiográfica oficial.

Promovendo um novo regime de memória, que se contrapôs ao longo silêncio sobre os indígenas na região, o movimento de reelaboração étnica e cultural no baixo Tapajós que ocorre na contemporaneidade está trazendo um novo repensar sobre o passado histórico, que se conforma para os próprios indígenas, para a academia, como para as instâncias do poder, que passam a incluí-los nos seus projetos de governança.

\section{Referências}

AMOROSO, Marta Rosa. 1992. "Corsários no Caminho Fluvial: os Mura no Rio Madeira". In: CARNEIRO DA CUNHA, Manuela (Org.). História dos Índios no Brasil. São Paulo: Cia. Das Letras, pp. 297-310.

BAENA, Antônio Ladislau Monteiro. 2004[1839]. Brasília: Senado Federal, Secretaria Especial de Editoração e Publicação. http://www2.senado.leg.br/bdsf/handle/id/1097

BALANDIER, Georges. 1993[1955]. "A noção de situação colonial”. Cadernos de Campo. São Paulo, n. 3: 107-131.

BARTOLOMÉ, Miguel A. 2006. As Etnogêneses: velhos atores e novos papéis no cenário cultural e político. Mana, Rio de Janeiro, v. 12, n. 1.

BATES, Henry W. 1979[1863]. Um Naturalista no Rio Amazonas. Belo Horizonte: Editora Itatiaia/USP

BENJAMIN, Walter. 1985. Obras Escolhidas Volume I: Magia e Técnica, Arte e Política. São Paulo: Editora Brasiliense.

BESSA FREIRE, José R. 2011. Rio Babel: A História das línguas na Amazônia. Rio de Janeiro: Editora da UREJ.

BOLANOS, Omaira. 2008. Constructing Indigenous Ethnicities and Claming Land Rights in the Lower Tapajós and Arapiuns region, Brazilian Amazon. Tese (Doutorado em Antropologia) - University of Florida, Gainesville, FL. 
COUDREAU, Henri. 1977[1897]. Viagem ao Tapajós. Belo Horizonte: Livraria Itatiaia.

DI PAOLO, Pasquale. 1990. Cabanagem: A revolução popular na Amazônia. Belém: CEJUP.

FATHEUER, Thomas. 1998. "Novos Caminhos para a Amazônia? O Programa Piloto do G-7: Amazônia no contexto internacional”. Série Cadernos de Proposta, n. 2. Rio de Janeiro, FASE/SACTERS.

GALVÃO, Eduardo. 1955. Santos e Visagens: Um estudo da vida religiosa de Itá. São Paulo: Cia Editora Nacional.

Harris, Mark. 2010. Rebellion on the Amazon: the Cabanagem, Race and popular Culture in the North of Brazil. Cambridge: University Press.

IORIS, Edviges M. 2005. A forest of disputes: struggles over spaces, resources and social identities in Amazônia. Tese de Doutorado, University of Florida, Gainesville-FL

IORIS, Edviges M. 2009. "Identidades negadas, identidades construídas: processos identitários e conflitos territoriais na Amazônia". Ilha (Revista de Antropologia), 11(1 e 2): 219-164.

IORIS, Edviges M. 2011. "Fragmentos que fazem diferença: narrativas indígenas na reconstrução do passado e das identidades étnicas". Antropologia em Primeira Mão, n. 125.

IORIS, Edviges M. 2014. Uma Floresta de Disputas: Conflitos sobre espaços, recursos e identidades sociais na Amazônia. Florianópolis: Editora UFSC.

IORIS, Edviges M. 2017. "De ruínas e fragmentos: narrativas e reflexões indígenas na reconstrução do passado e das identidades étnicas". In: Ricardo Verdum; Edviges M loris. (Org.). Autodeterminação, autonomia territorial e acesso à justiça: povos indígenas em movimento na América Latina. Rio de Janeiro: Associação Brasileira de Antropologia (ABA), pp. 229-251.

IORIS, Edviges M. 2018. "Memory regimes, struggles over resources and ethnogenesis in the Brazilian Amazon". Vibrant, v. 15, n. 2 | May - August 2018.

LEROY, Jean P. 1991. Uma chama na Amazônia. Rio de Janeiro: Vozes/FASE Editora.

LIMA, Deborah M. 2002. "A construção histórica do termo caboclo: sobre estruturas e representações sociais no meio rural Amazônico". Novos Cadernos NAEA, 2(2): 5-32.

LIMA, Leandro M. 2015. No Arapiuns, entre verdadeiros e - ranas: sobre os espaços, as lógicas, as organizações e os movimentos do político. Tese (Doutorado em Antropologia). São Paulo: Universidade de São Paulo.

LIMA, Leandro M. 2008. Rios Vermelhos: Perspectivas e posições de sujeito em torno da noção de cabano na Amazônia em meados de 1835. Dissertação (Mestrado em Antropologia). São Paulo: Universidade de São Paulo.

LINS E SILVA, Tatiana. 1980. Os curupiras foram embora: economia, política e ideologia em uma comunidade amazônica. Dissertação (Mestrado em Antropologia). Museu Nacional/Universidade Federal do Rio de Janeiro, Rio de Janeiro. 
MEGGERS, Betty. 1977. Amazônia: a ilusão de um paraíso. Rio de Janeiro: Civilização Brasileira.

MENÉNDEZ, Miguel. 1981. "Uma contribuição para a etno-história da área TapajósMadeira". Revista do Museu Paulista (Nova Série), v. 28, pp. 289-385.

MENÉNDEZ, Miguel. 1992. “A Área Madeira-Tapajós. Situação de Contato e Relações entre Colonizador e Indígenas". In: CUNHA, M. C. (Org.). História dos Índios do Brasil. São Paulo: Companhia das Letras, pp. 315-329.

MOREIRA NETO, Carlos A. 1988. Índios da Amazônia, de maioria a minoria (17501850). Petrópolis: Editora Vozes.

MOTA, Maria das Graças. 2006. Indígenas: Organización y Recuperación Territorial. Um Sueño de Lucha em la Amazônia Brasileña del Bajo Tapajós. Dissertação (Mestrado em Antropologia) - Pós-Graduação em Derechos Internacionales Indígenas y Recursos Hidrocarburíferos. FLACSO: Quito (Equador).

NIMUENDAJÚ, Curt. 1949. "Os Tapajó". Boletim do Museu Paraense Emilio Goeldi, 10: 93-106.

OVERING, Joanna. 1990. The Shaman as a Maker of Worlds: Nelson Goodman in the Amazon. Man, New Series, 25(4):602-619.

PACHECO de OLIVEIRA, João. 1988. O Nosso Governo: Os Ticuna e o regime tutelar. São Paulo/Brasília: Editora Marco Zero/MCT-CNPq,

PACHECO de OLIVEIRA, João. 1999. A viagem da volta: Etnicidade, política e reelaboração cultural no Nordeste indígena. Rio de Janeiro: Contra Capa.

PACHECO de OLIVEIRA, João. 2016. O Nascimento do Brasil e Outros Ensaios: "pacificação", regime tutelar e formação de alteridades. Rio de Janeiro: Conta Capa.

PACHECO de OLIVEIRA, João e ROCHA FREIRE, Carlos Augusto da. 2006. A Presença Indígena na Formação do Brasil. Brasília: Ministério da Educação, Secretaria de Educação Continuada, Alfabetização e Diversidade; LACED/Museu Nacional.

PARKER, Eugene. 1985. The Amazon caboclo: historical and contemporary perspectives, Studies in Third World societies. Williamsburg: College of William and Mary.

PEIXOTO, Kércia Priscilla Figueiredo. 2017. "EU EXISTO”: afirmação indígena e nomeação do racismo. Os Borari e os Arapium da Terra Maró, Amazônia. Tese (Doutorado em Antropologia), Universidade Federal do Pará.

SANTOS, Paulo R. 1999. Tapaiulândia. Santarém: Gráfica e Editora Tiagão.

SIDER, Gerald. 1976. Lumbee Indian Cultural Nationalism and Ethnogenesis. Dialectical Anthropology, 1(2):161-172

TASSINARI, Antonella M.I. 2003. No bom da festa: o processo de construção cultural das famílias karipuna do Amapá. São Paulo: EDUSP.

TAUSSIG, Michael. 1984. History as Sorcery. Representations, 7(Summer 1984):87-109. VAZ, Florêncio de Almeida. 2010. A emergência étnica de povos indígenas no Baixo Rio Tapajós, Amazônia. Tese (Doutorado em Antropologia) - Universidade Federal da Bahia, 


\section{Salvador.}

VELTHEM, Lucia Hussak van. 2003. O Belo é a Fera: A estética da produção e da predação entre os Wayana. Lisboa: Assírio \& Alvim.

WAGLEY, Charles. 1976. Amazon Town: A study of man in the Tropics. New York: Alfred A. Knopt. 